\title{
Manufacturer-Dealer Relationships. The Influence of Trust and Commitment to Technological Interface Adoption
}

\author{
José R. Concha \\ Universidad Icesi, Cali, Colombia \\ Email: jrconcha@icesi.edu.co
}

Received July 16, 2013; revised August 10, 2013; accepted August 16, 2013

Copyright (C) 2013 José R. Concha. This is an open access article distributed under the Creative Commons Attribution License, which permits unrestricted use, distribution, and reproduction in any medium, provided the original work is properly cited.

\begin{abstract}
The steep increase in the number and variety of exchange relations, the increased complexity and uncertainty of the business environment cannot be managed without the presence of interpersonal and/or interorganizational trust and relationship commitment. Manufacturer firms have to pay close attention to developing and maintaining relationship commitment and dealers' trust. The value of such efforts is the most apparent when high levels of competition threaten market shares and the stability of the dealers' network. This empirical study shows that trust and relationship commitment are important assets for the technological interface adoption and bring significant savings for the manufacturer and dealer.
\end{abstract}

Keywords: Trust; Marketing Relationship; Technological Interface; Commitment

\section{Introduction}

Understanding relationship marketing requires distinguishing between a discrete transaction, with a distinct beginning, short duration, and sharp ending by performance, and relational exchange, which relies on previous agreements and is longer in duration, reflecting an ongoing process [1]. Categorized with reference to a dealer and its relational exchange with the manufacturer, there are two forms of relationship marketing: one is the relational exchange to obtain the goods on time, and the other is the strategic alliance between the dealer and the manufacturer obtaining a "total quality management." This second form builds a stronger relationship as a way to earn the position of preferred supplier by developing trust in the dealers over a period of time.

\section{Antecedents of Trust}

In the manufacturer-dealer context, the supplier firm provides elements to encourage trust in the dealer through its policies, actions, and personnel [2].The major characteristics of the firm to influence trust development in the dealer are: 1) supplier reputation; 2) manufacturer size; 3) manufacturer's willingness to customize for buyer; 4) manufacturer confidential information sharing; and 5) length of the relationship with manufacturer.

\section{Model}

This study analyzes (Figure 1) how the dealer's trust and relationship commitment influences the adoption of technological interface. For the study, trust is considered the willingness to rely on an exchange partner in whom one has confidence. This definition highlights the importance of confidence. The literature on trust suggests that confidence that the trustee is reliable and has high integrity is associated with such qualities as consistency, competence, honesty, fairness, responsibility, and benevolence [3].

The other initial variable in the model is relationship commitment, which is defined as an exchange partner believing that an ongoing relationship with another is so important as to warrant maximum efforts at maintaining it [4].

Included in the model for the empirical study is also the adoption of technological interface, which is affected by the influence of relationship commitment and trust, as well as by four external observed variables which are: operational benefits, financial benefits, accessibility, and relational benefits. 


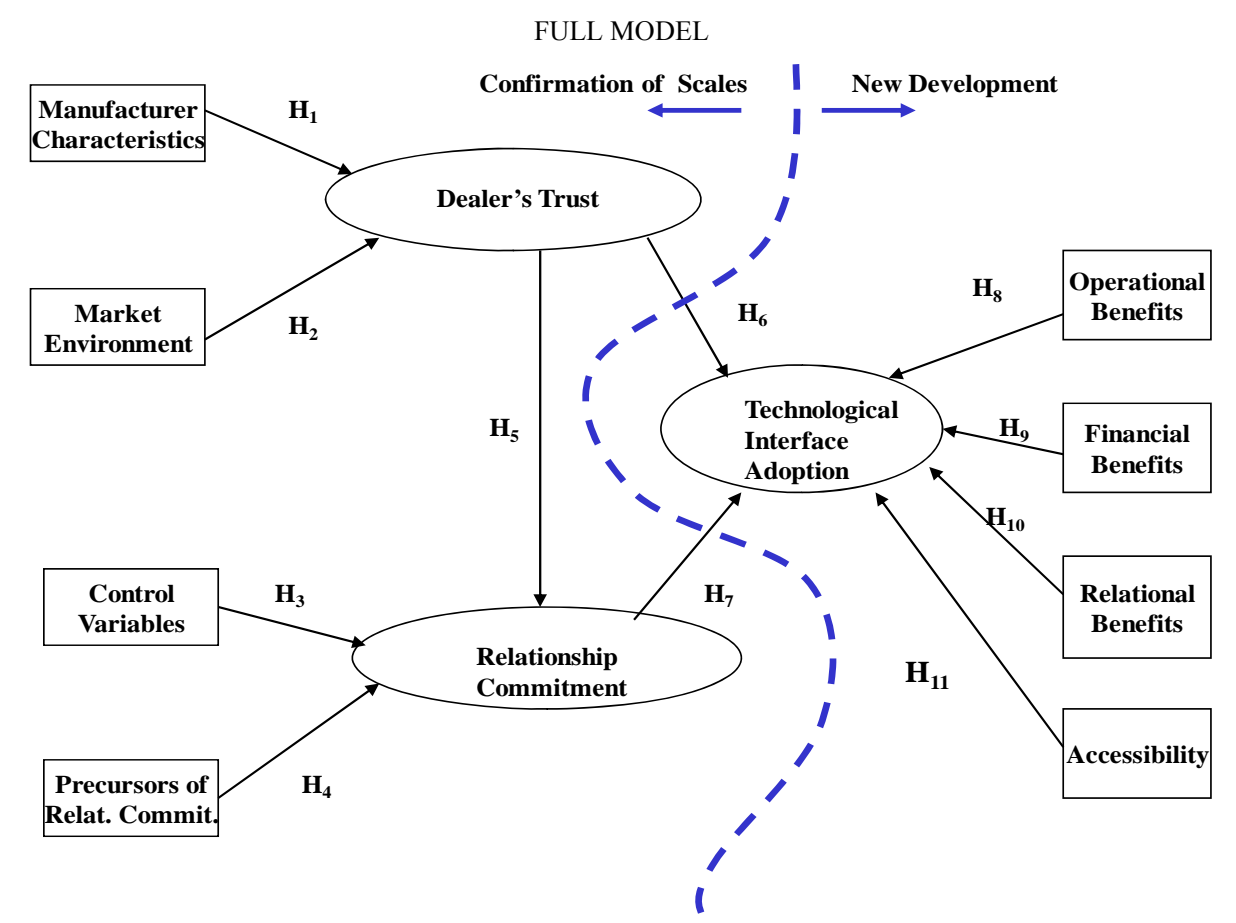

Figure 1. The influence of relationship commitment and dealer's trust in adopting technological interface.

\subsection{Characteristics of the Manufacturer}

Characteristics of the manufacturer play an important role in relations with the dealers and in building a longterm oriented partnership. To better understand these relationships, I will explain the main factors necessary for an overall perspective and definition of a manufacturer firm and their effect on the trust-building in the relationship.

$\mathrm{H}_{1}$ : A dealer's trust is directly related to manufacturer characteristics.

The market environment has a significant effect on decision-making uncertainty in making channel relations [5]. Because different facets of uncertainty have opposite effects on channel structure and channel member behavior [6], five dimensions of market environment predictability, accuracy, certainty, complexity, and stability, were examined by Ganesan [7] who found that they have strong effects on the trust of organizations. These dimensions will be evaluated again in the present study. The previous analysis supports our next hypothesis and states that.

$\mathrm{H}_{2}$ : A dealer's trust is directly related to market environment.

\subsection{Manufacturer Performance}

Considerable empirical and anecdotal evidence suggests that the primary criteria for current manufacturer selection decisions and future purchase intentions involve manufacturer performance which is named by Doney and
Canon [2] as control variables. Reviewing the organizational buying literature revealed three aspects of manufacturer performance that consistently emerged as central to the dealer's evaluation of a manufacturer's product offering: 1) delivery performance; 2) relative price/cost; and 3) product/service performance [8].

$\mathrm{H}_{3}$ : A dealer's relationship commitment is directly related to manufacturer performance.

\subsection{Relationship Commitment}

The major precursors of relationship commitment were identified in Chapter I as: relationship termination costs, communications, and opportunistic behavior. Morgan and Hunt [4] and studied the effects of these factors, concluding that they positively affect relationship commitment.

In this research, I am measuring the same factors, using their questionnaire designed for automobile tire retailers in the United States of America. Then the conclusions obtained in this study can be used also as a crosscultural evaluation of the hypothesis:

$\mathrm{H}_{4}$ : There is a positive relationship between precursor's factors and relationship commitment.

\subsection{Dealer's Trust}

As a variable that reduces risk, trust supports close relations and cooperation. However, when a party believes that a partner engages in opportunistic behavior, such behavior most of the time results in a decrease of rela- 
tionship commitment because partners believe that they can no longer trust one another. Thus, when talking about commitment and cooperation, I posit that firms that receive benefits from their relationship will be committed to its development in the future as well [9].

I propose that trust is a major determinant of relationship commitment, as does Achrol [10]; hence, we hypothesized that:

$\mathrm{H}_{5}$ : Relationship commitment is directly related to a dealer's trust.

\subsection{Technological Interface Adoption}

Technology has significantly influenced the ways in which people communicate and exchange information both within and among organizations. The development and growing use of technology in all areas of life have brought about a need to take into account this variable into business relationships [11]. While in the past, suppliers were mainly dependent on the work and feedback of the manufacturers and dealers, now they are discovering the advantages of technological interface. However, one common thread in the electronic communication literature is that messages sent via e-mail are, in their current text-based format, lacking when it comes to conveying certain types of information [12]. From these facts we can conclude that:

$\mathrm{H}_{6}$ : There is a positive relationship between technological interface adoption and relationship commitment.

$\mathrm{H}_{7}$ : There is a positive relationship between technological interface adoption and dealer's trust.

\subsection{Technological Interface Antecedents}

The decision to adopt new technologies is difficult because of the associated uncertainties: switching costs in equipment and training, the necessity to develop new skills with the personnel, the possibility that the technology will become obsolete quickly, accessibility problems that interface technology has in developing countries, difficulties evaluating the real incomes that the new technology adoption will have for the dealer's business in terms of financial and managerial benefits, and the responsibility in terms of the relationship with the manufacturer [13].

For that reason, a company decision to adopt new technologies is linked to its business strategy, because it will be affected by the level of the relationship and the dealer's trust in the manufacturer.

\subsection{Operational Benefits}

Operational benefits are defined as the adopter beliefs of the likelihood that the technological interface adoption can improve the quality, security, opportunity, and reliability of the information. Benefits may come from qual- ity improvement, timely information to his/her customers, new market development, improvement in job performance and the associated intrinsic and extrinsic rewards. Hence, it is hypothesized that

$\mathrm{H}_{8}$ : A dealer's technological interface adoption is directly related to operational benefits.

\subsection{Financial Benefits}

I consider that the prospective adopter's subjective probability that applying the new technology from the manufacturer will be economical beneficial to his personal and/or the adopting company's well-being. To the adopting organization, utility means economic or financial benefits resulting from adopting new technology. These benefits may consist in reduces inventory, increases profitability, increases sales, reduces delivery costs, improves delivery times, and makes delivery more accurate.

$\mathrm{H}_{9}$ : A dealer's technological interface adoption is directly related to financial benefits.

\subsection{Relational Benefits}

The adoption of new technology carries a high risk, then the level of perceived commitment from the manufacturer can help reduce this risk though the transmission of adequate information from the manufacturer to the dealer. The relational benefits perceived by the dealer are very critical and affect the dealer's interest to absorb the technology. The more extensive the relational benefits, the more positive are the interest to adopt the new form of technology. Thus, we hypothesized that:

$\mathrm{H}_{10}$ : A dealer's technological interface adoption is directly related to relational benefits.

\subsection{Accessibility}

I defined accessibility as the degree to which the perceived application of new technological interface is free of efforts. The lower the difficulty to use the new technology, the lower is the level of perceived risk and the higher is the probability of a successful adoption. Measures of this construct reflect the potential difficulty for the adopting firm to use the technology, as well as the satisfaction degree that the user has with its adoption. Therefore, the following hypothesis is:

$\mathrm{H}_{11}$ : A dealer's technological interface adoption is directly related to accessibility.

\section{Method}

For the study, we use the data from a sample of Goodyear tire dealers in Colombia. All the Colombian tire dealers are independent and, thus, are able to make free choices and decisions about the manufacturers of the 
products they sell. Most of the dealers are family-run businesses or assigned distributors that cooperate with the big automobile tire manufacturers and sell their products to the customers.

\subsection{Sample}

To construct the sample of dealers, we asked Goodyear to assist and supply us with lists of their 128 retailers in the Colombian territory that represent the total population of the Goodyear dealers. This list was the sample for the research.

\subsection{Measure Development}

To be in agreement with previous studies made by other researchers, preexisting scales will be identified where possible and will be adapted to this study. Then, trust in manufacturer characteristics was measured by adapting Doney and Cannon's [2] questionnaire. Market environment was measured using the questionnaire adapted from Ganesan [7]. Relationship commitment was measured by adapting the questionnaire from Morgan and Hunt [4]. For the measure of control variables, we use the scales developed by Ganesan [7]. Because a scale for one key construct in my research, technological interface, was not available, we developed a scale then applied an appropriate refinement procedure [14]. Table 1 show the differ-

Table 1. Description of variables.

\begin{tabular}{|c|c|c|}
\hline $\begin{array}{l}\text { Latent } \\
\text { Exogenous }\end{array}$ & $\begin{array}{l}\text { Latent } \\
\text { Endogenous }\end{array}$ & Observable \\
\hline \multirow{9}{*}{ Dealer's trust } & \multirow{5}{*}{$\begin{array}{l}\text { Manufacturer } \\
\text { Characteristics Doney } \\
\text { and Cannon (1997) }\end{array}$} & Manufacturer Reputation \\
\hline & & Manufacturer Size \\
\hline & & Mfr. Willingness to Customize \\
\hline & & Mfr. Confidential Inf. Sharing \\
\hline & & Length of Relationship \\
\hline & \multirow{4}{*}{$\begin{array}{l}\text { Market Environment } \\
\text { Ganesan (1994) }\end{array}$} & Predictability \\
\hline & & Accuracy \\
\hline & & Certainty \\
\hline & & Complexity \\
\hline \multirow{6}{*}{$\begin{array}{l}\text { Relationship } \\
\text { Commitment }\end{array}$} & \multirow{3}{*}{$\begin{array}{l}\text { Relationship } \\
\text { Commitment Morgan } \\
\text { \& Hunt (1994) }\end{array}$} & Relationship Termination Costs \\
\hline & & Communications \\
\hline & & Opportunistic Behavior \\
\hline & \multirow{3}{*}{$\begin{array}{l}\text { Control Variables } \\
\text { Doney \& Canon } \\
\text { (1994) }\end{array}$} & Delivery Performance \\
\hline & & Relative Price/Cost \\
\hline & & Product/Service \\
\hline \multirow{4}{*}{$\begin{array}{l}\text { Technological } \\
\text { Interface }\end{array}$} & \multirow{4}{*}{ Usage Characteristics } & Operational Benefits \\
\hline & & Financial Benefits \\
\hline & & Relational Benefits \\
\hline & & Accessibility \\
\hline
\end{tabular}

ent variables included in our survey.

\section{Results}

All measures were analyzed for validity and reliability following the guidelines supplied by Jöreskog and Sörbom [15]. The full model measured through a confirmatory factor analysis using LISREL 8.52 shows a good fit with $\chi_{(101)}^{2}=117.04(\mathrm{p}=0.131)$ which is not significant at 0.05 ; suggesting that the proposed model is consistent with the observed data. Below I discuss in detail each of the partial models and the origins of the measures used.

\subsection{Influence of Manufacturer Characteristics on Dealer's Trust}

The five observed variables used in this study were manufacturer firm reputation, manufacturer firm size, and manufacturer firm willingness to customize for the dealer, manufacturer confidential information sharing, and length of relationship with the dealer. These measures of dealer's trust on the manufacturer were obtained from Doney and Canon's [2] study. The observed variables exhibit a good reliability, with lower values for size $(\alpha=0.53)$ and reputation $(\alpha=0.58)$, but we obtain Cronbach alpha over 0.70 for the other variables.

For assessing discriminant validity, we conducted exploratory factor analysis to ensure high loadings on hypothesized factors and low cross-loadings. The test provided evidence of discriminant validity among all the observed variables in the set, but different to the Doney and Canon [2] decision, who removed reputation construct from the set for further analysis because the construct shows high cross loadings, we included it because this variable did not show high cross loadings and, for the market studied in this research, manufacturer reputation is a very big asset for the dealers.

We used two methods for assessing convergent validity; one was the LISREL estimates of paths from individual items to latent factors that were all statistically significant $(p<0.01)$, and the other was the results of the exploratory factor analysis showed no high cross loadings.

We evaluated the properties of all the observed variables by conducting a confirmatory factor analysis on the covariance matrices using LISREL 8.52. The reliability analysis for the five observed variables considered shows a relatively good Cronbach alpha value of $\alpha=0.60$. The chi-squared statistic was statistically non significant $\left(\chi_{(5)}^{2}=5.7 ; \mathrm{p}=0.33\right)$, which is very good. The absolute goodness of fit indexes RMSEA $=0.04, \mathrm{GFI}=0.97$, and AGFI $=0.91$ suggests that these data provide a good fit with the hypothesized measurement model, the $\mathrm{H}_{1}$ is accepted. 


\subsection{Influence of Market Environment on Dealer's Trust}

We used measures of market environment influence on dealer's trust from Ganesan [7] that was adapted for this research. All the five items considered were included in six questions of the survey, evaluating: accuracy, predictability, certainty, complexity, and stability. However the reliability analysis (see Appendix I) shows a very low Cronbach alpha value (0.31), the Kaiser-Meyer-Olkin measure of sampling adequacy is only 0.66 , and the exploratory factor analysis shows high cross-loadings between the measures.

Taking in account the previous statistical results, it is important to consider the market environment in the context of this research: Colombia, as an undeveloped country, does not have a stability situation in the longterm, then the small and medium enterprises in this country does not consider the stability as an important factor when they evaluate the market environment, because they are living for decades under unstable circumstances handling their business. Therefore, I made the decision to remove the stability construct for further analysis.

With the remaining four constructs accuracy, predictability, certainty and complexity, the reliability Cronbach alpha value is 0.66 , which is relatively good. Also the group shows a Kaiser-Meyer-Olkin measure of 0.72 , and the cross-loadings were reduced in the factor analysis.

The evaluation of the properties of the four observed variables was made conducting a confirmatory factor analysis on the covariance matrices using LISREL 8.52. The reliability analysis for the four observed variables, considered as the constructs, shows a good Cronbach alpha value of $\alpha=0.66$. The chi-squared statistic was statistically non significant $\left(\chi_{(26)}^{2}=35.77 ; \mathrm{p}=0.10\right)$, which is very good. The absolute goodness of fit indexes RMSEA $=0.08$, GFI $=0.90$, and AGFI $=0.83$, and the standardized residuals were generally small and non significant. These results confirm the $\mathrm{H}_{1}$ hypothesis.

\subsection{Influence of Manufacturer Performance on Relationship Commitment}

To measure the influence of manufacturer performance on relationship commitment, we used the scale proposed by Doney and Canon [2], which includes three groups of constructs: supplier performance, purchase experience with the vendor, and purchase choice. In the present research, our sample is uni-brand tire dealers, because they do not have purchase choice and the purchase experience is unique with Goodyear, I used the scale with the supplier performance that include three aspects of manufacturer: 1) delivery; 2) relative price/cost; and 3) product/service performance.
Reliability (coefficient alpha) for the groups ranges from 0.62 for delivery performance, 0.66 for relative price/cost, and 82 for product/service performance. We used exploratory factor analysis to confirm high loadings on hypothesized factors and low cross-loadings. The test provided evidence of discriminant validity among all the observed variables in the set.

To assess convergent validity, we took into consideration the paths from individual items to latent factors, obtained using LISREL 8.52, that was all statistically significant $(\mathrm{p}<0.01)$. The reliability analysis for the group of three observed variables considered to measure relationship commitment shows a relatively good Cronbach alpha value of $\alpha=0.70$. The model using LISREL shows that is saturated, which means it has as many parameters as there are non-redundant elements in the covariance matrix, and then the model fit perfectly, and the $\mathrm{H}_{3}$ is confirmed.

\subsection{Influence of Precursors of Relationship Commitment}

The items used to confirm this hypothesis came from the scale developed by Morgan and Hunt [4] and were adapted in the dealers' questionnaire. The analysis of the variables in the group shows a good reliability Chronbach alpha index, with $\alpha=0.87$ for relationship termination cost, $\alpha=0.87$ for communication, and $\alpha=0.84$ for opportunistic behavior. The global scale reliability for this group of antecedents all shows a good level of $\alpha=$ 0.67 .

Examining assessed convergent validity of the facet scales and the global scale whether each indicator's pattern coefficient from the measurement model was significant. This is what Bagozzi [16] calls "convergence in measurement," because the t-value of each item is greater than 2 in all three paths of the measurement model. In this case, we obtained through LISREL a saturated model that fits perfectly and the $\mathrm{H}_{4}$ is also confirmed positively.

\subsection{Influence of Observed Variables on Technological Interface Adoption}

As the questionnaire used in this group was developed based on the initial survey, initially we conducted an exploratory factor analysis to evaluate ensuring high loadings on hypothesized factors and low cross-loadings. The test provided evidence of four important factors to build the scale: operational benefits, managerial benefits, relational benefits, and accessibility. The data obtained for the reliability test were: $\alpha=0.92$ for operational benefits, $\alpha=0.90$ for managerial benefits, $\alpha=0.79$ for relational benefits, and $\alpha=0.69$ for accessibility.

Cronbach alpha for the technological interface adoption is good $(\alpha=0.82)$. The descriptive statistics indicate 
that the dealers in our sample rated themselves as rather more prone to adopt technological interface because the mean score of 132.62 (range 25 to 175 ) and a standard deviation of 24.94. Our model for the antecedents of technological interface adoption yields non-significant with $\chi_{(2)}^{2}=0.30 ; p=0.86$, which is very good. The fit indexes were for root mean square residual, $\mathrm{RMR}=0.01$, for root mean square error of approximation, RMSEA = 0.00 , for goodness of fit index, GFI $=1.00$, and for adjusted goodness of fit index, AGFI $=0.99$.

\subsection{Full Model: Influence of Trust and Relationship Commitment on Technology Interface Adoption}

To evaluate the full model we created a more detailed procedure evaluating the assessment individually:

\subsubsection{Assessment of Reliability}

To assess reliability, I used Cronbach's alpha index for each of the observed variables in the model, and for the global scales; the individual reliabilities for the variables were reported in the previous results, and the global scale exhibits high reliability with $\alpha=0.88$ [17].

\subsubsection{Assessment of Convergent Validity}

Convergent validity was evaluated by examining whether each indicator pattern coefficient from the measurement model was significant. The $t$ values for each parameter were supplied by the LISREL program, showing that all of them have a value greater than +2 or less than -2 ; then the parameters are referred to as significant and can be considered distinct from 0 in the population [18].

\subsubsection{Assessment of Discriminant Validity}

To establish discriminant validity between the facets, we used the final model as the base model. Constraining the phi value for a pair of variables to unity and then estimating the resulting measurement model assessed discriminant validity. Because the base model gave a significantly better fit than the constrained model, it indicates that the traits are not perfectly correlated, and discriminant validity was achieved.

\subsection{The Final Model}

The resulting measurement full model (see Table 2) through a confirmatory factor analysis using LISREL 8.52 shows a good fit with $\chi_{(101)}^{2}=117.04(\mathrm{p}=0.131)$, which is not significant at 0.05 . I remember that this way of looking at statistical inference in structural equation modeling may appear to be reverse at the one used in the framework of traditional hypothesis testing [18]. The model fit is as follows: $\mathrm{RMR}=0.09$, $\mathrm{RMSEA}=0.05$, $\mathrm{GFI}=0.76, \mathrm{AGFI}=0.68, \mathrm{NFI}=0.83, \mathrm{NNFI}=0.93$ and
Table 2. Full model. Factor loadings and errors.

\begin{tabular}{|c|c|c|c|}
\hline Observed Variable & $\begin{array}{c}\text { Latent } \\
\text { Variable }\end{array}$ & $\lambda$ & e \\
\hline Manufacturer Reputation & \multirow{6}{*}{$\begin{array}{l}\text { Dealer's } \\
\text { Trust }\end{array}$} & 0.79 & 3.36 \\
\hline Manufacturer Size & & 1.18 & 5.16 \\
\hline Manufacturer Willingness & & 4.94 & 1.34 \\
\hline $\begin{array}{l}\text { Manufacturer Confidential } \\
\text { Information Sharing }\end{array}$ & & 1.67 & 3.51 \\
\hline Length of Relationship & & .43 & 3.71 \\
\hline Market Environment & & 1.21 & 25.70 \\
\hline Delivery Performance & \multirow{5}{*}{$\begin{array}{l}\text { Relationship } \\
\text { Commitment }\end{array}$} & 1.23 & 2.27 \\
\hline Service Performance & & 1.34 & 6.73 \\
\hline Relationship Termination Costs & & 5.88 & 28.74 \\
\hline Communications & & 3.73 & 11.44 \\
\hline Opportunistic Behavior & & 3.02 & 13.88 \\
\hline Operational Benefits for Dealer & \multirow{4}{*}{$\begin{array}{c}\text { Technological } \\
\text { Interface } \\
\text { Adoption }\end{array}$} & 8.98 & 46.98 \\
\hline Financial Benefits for Dealer & & 7.54 & 19.97 \\
\hline Relation. Benefits for Dealer & & 2.06 & 9.30 \\
\hline Accessibility & & 5.63 & 6.96 \\
\hline
\end{tabular}

CFI $=0.94$. In summary, the full model for technological interface adoption shows an acceptable fit.

The size of the factor loadings $(\lambda)$ in the Table 2, indicates how much they contribute to predicting or to measuring the latent variable. Based on the final model obtained, we can establish the importance that the factors have for the different latent variables:

Manufacturer willingness to customize for dealer has an important influence developing dealer's trust $(\lambda=$ 4.94).

Relationship termination cost is the observed variable affecting considerably the relationship commitment of the dealer $(\lambda=5.88)$.

The adoption of technological interface has three most important observed variables with high loading factors; operational benefits $(\lambda=8.98)$, financial benefits $(\lambda=$ $7.54)$, and accessibility $(\lambda=5.63)$.

\subsection{Total Effects}

The structural equation model permits obtaining both the direct and indirect effects of the various variables included in the model. Direct effects are the effects that go directly from one variable to a second variable and were evaluated previously. Indirect effects are the effects between two variables that are mediated by one or more intervening variables, often referred to as a mediating variable. The combination of direct and indirect effects makes up the total effect of the explanatory variable on a dependent variable. For this research the mediating variable is the technological interface adoption. The total effects of the observed variables on trust and relationship 
commitment are in Table 3.

\section{Conclusions}

In the business-to-business markets, relationship commitment nowadays is one of the "order qualifiers", where the firms are more oriented to achieving future goals with long-term outcomes. This study shows that the adoption of technology interface is possible if the manufacturer has developed relationship commitment and trust in its dealers. The paths from trust and relationship commitment to technological interface in the full model show a positive sign for the regression coefficient between relationship commitment and technological interface adoption and a negative value for the factor loading between trust and technological interface adoption. This result reflects the following findings: high levels of relationship commitment are expected to cause high levels of technological interface adoption; in contrast, high levels of dealer's trust are expected to generate low levels of technological interface adoption.

Furthermore, I confirm that the operational benefits, financial benefits, relational benefits, and accessibility influence the adoption of new forms of technology that facilitate the communication and operations between the manufacturer and the dealers. The effects of each of the paths showing these influences determine the importance that they have in the adoption of new forms of technology. Moreover, the total effects on relationship commitment and trust are very important findings to be taken into account for the manufacturers.

In Colombia, under different cultural influences, we were able to confirm the findings made by other researchers. Both dealers focus on the characteristics of the firm [2] and on the market environment [7] to develop trust. However, in Colombia unlike in the US, the manufacturer characteristic of reputation must be taken into account. In the survey study developed by Doney and Canon [2] with a sample from members of the National Association of Purchasing Management, this reputation construct was removed.

In reference to the market environment influence to develop trust, dissimilar to Ganesan [7] survey, I find that the stability construct is not an important element for the Colombian Goodyear dealers in the trust-building process.

Table 3. Total effects on latent variables.

\begin{tabular}{ccc}
\hline & Trust & Relationship Commitment \\
\hline Operational benefits & -5.02 & 13.73 \\
Financial benefits & -4.22 & 11.53 \\
Relational benefits & -1.15 & 3.15 \\
Accessibility & -3.15 & 8.61 \\
\hline
\end{tabular}

We also used the scales developed by Morgan and Hunt [4] to determine the precursors of relationship commitment. The samples in both studies were independent automobile tire retailers, and then the findings showed a cross-cultural evaluation of the process. Finally, in this study, we confirmed that the control variables were antecedents of relationship commitment, according with the scales developed by Doney and Canon [2].

The manufacturers should promote strongly the adoption of technological interface by the dealers. The development of this kind of communication represents an investment with a long-term payoff. Therefore, when the manufacturer considers the costs and benefits of investing in developing a technological interface, it must consider that relationship commitment and dealer's trust are factors that influence positively the adoption process. The fact is that trust and relationship commitment developed in a dealer brings about bigger benefits than cooperation alone.

Manufacturer firms have to pay close attention to developing and maintaining relationship commitment and dealers' trust [19]. The value of such efforts is the most apparent when high levels of competition threaten market share and the stability of the dealers' network. With this study I showed that trust and relationship commitment were important assets for the technological interface adoption and bring significant savings for the manufacturer and dealer.

In summary, in all demand situations, the adoption of technology interface requires the consideration of external and internal variables. For the manufacturers, it is advisable to "market" the technology on its operational and financial benefits and accessibility but also considering the relationship commitment and trust building with their dealers.

\section{REFERENCES}

[1] F. R. Dwyer, P. H. Schurr and S. Oh, "Developing BuyerSeller Relationships," Journal of Marketing, Vol. 51, No. 2, 1987, pp. 11-27. doi:10.2307/1251126

[2] P. M. Doney and J. P. Cannon, "An Examination of the Nature on Trust in Buyer-Seller Relationships," Journal of Marketing, Vol. 61, No. 2, 1997, pp. 35-51. doi: $10.2307 / 1251829$

[3] I. Altman and D. A. Taylor, "Social Penetration: The Development of Interpersonal Relationships," Holt, Rinehart, and Winston, New York, 1973.

[4] R. M. Morgan and S. D. Hunt, "The Commitment-Trust Theory of Relationship Marketing," Journal of Marketing, Vol. 58, No. 3, 1994, pp. 20-38. doi:10.2307/1252308

[5] R. S. Achrol, L. K. Scheer and L. W. Stern, "Designing Successful Transorganizational Marketing Alliances," Marketing Science Institute, Working Paper No. 90-118, Marketing Science Institute, Cambridge, 1990. 
[6] S. Balakrishnan and B. Wernerfelt, "Technical Change, Competition and Vertical Integration," Strategic Management Journal, Vol. 7, No. 4, 1986, pp. 347-359. doi:10.1002/smj.4250070405

[7] S. Ganesan, "Determinants of Long-Term Orientation in Buyer-Seller Relationships," Journal of Marketing, Vol. 58, No. 2, 1994, pp. 1-19. doi:10.2307/1252265

[8] E. J. Wilson, "The Relative Importance of Supplier Selection Criteria: A Review and Update," International Journal of Purchase and Materials Management, Vol. 30, No. 2, 1994, pp. 35-41.

[9] A. Wong and A. Sohal, "An Examination of the Relationship between Trust, Commitment and Relationship Quality," International Journal of Retail \& Distribution Management, Vol. 30, No. 1, 2002, pp. 34-50. doi:10.1108/09590550210415248

[10] R. Achrol, "Evolution of the Marketing Organization: New forms for Turbulent Environments," Journal of Marketing, Vol. 55, No. 4, 1991, pp. 77-93. doi:10.2307/1251958

[11] O. Turel, Y. Yuan and C. E. Connelly, "In Justice We Trust: Predicting User Acceptance of e-Customer Services," Journal of Management Information Systems, Vol. 24, No. 4, 2008, pp. 123-151. doi:10.2753/MIS0742-1222240405

[12] N. F. Awad and A. Ragowsky, "Establishing Trust in Electronic Commerce through Online Word of Mouth: An
Examination across Genders," Journal of Management Information Systems, Vol. 24, No. 4, 2008, pp. 101-121. doi:10.2753/MIS0742-1222240404

[13] D. J. Kim, D. L. Ferrin and H. R. Rao, "A Trust-Based Consumer Decision-Making Model in Electronic Commerce: The role of Trust, Perceived Risk, and Their Antecedents," Decision Support Systems, Vol. 44, No. 2, 2008, pp. 544-564. doi:10.1016/j.dss.2007.07.001

[14] G. A. Churchill, "A paradigm for Developing Better Measures of Marketing Constructs," Journal of Marketing Research, Vol. 16, No. 1, 1979, pp. 64-73. doi: $10.2307 / 3150876$

[15] K. G. Jöreskog and D. Sörbom, "User's Reference Guide," Scientific Software, Mooresville, 2000.

[16] R. P. Bagozzi, "Evaluating Structural Equation Models with Unobservable Variables and Measurement Error: A Comment," Journal of Marketing Research, Vol. 18, No. 3, 1981, pp. 375-381. doi:10.2307/3150979

[17] J. C. Nunally, "Psychometric Theory," 2nd Edition. McGraw Hill Book, New York, 1978.

[18] T. Raykov and G. Marcoulides, "A First Course in Structural Equation Modeling," Lawrence Erlbaum Associates, Publishers, Mahwah, 2000.

[19] D. Peppers andM. Rogers, "Customer Loyalty: A Matter of Trust," Sales \& Marketing Management, Vol. 158, No. 5, 2006, p. 22. 